\title{
Technology-mediated PBLT: Encouraging Japanese EFL Learners to Communicate in L2
}

\author{
Younghyon $\mathrm{Heo}^{1 *}$ \\ ${ }^{1}$ Center for Language Research, University of Aizu, Japan
}

\begin{abstract}
This study reports on the result of implementing online intercultural communication as a pre-PBLT activity to encourage the English learners of Japanese to use L2 during the project in an EFL context. Self-evaluation of their English speaking confidence level was conducted at three different stages of the project to track the change of Japanese EFL learners' confidence level before and after the completion of intercultural communication and finally after the completion of the entire project. Measuring the L2 speaking confidence level at three stages of our PBLT course allowed us to examine 1) whether the pre-PBLT intercultural communication successfully primed the Japanese EFL learners to speak in L2 in the subsequent PBLT activities, and 2) whether the Japanese EFL learners could maintain the "English-speaking mode" even during their communication with other Japanese speakers. The results indicate that most of the participants could successfully build L2 speaking confidence after the pre-PBLT intercultural communication and maintain the raised L2 speaking confidence by practicing L2 communication for the completion of the PBLT project with their Japanese partners.
\end{abstract}

\section{Introduction}

This paper reports on the process and the result of implementing the intercultural communication sessions designed to encourage Japanese EFL learners to use L2 during their tasks conducted in a university PBLT (Project-Based Language Teaching) class. One of the challenges of implementing PBLT in an EFL setting is students' predominant use of L1 when the learners share the same native language in a given EFL class. In this study, we implemented a pre-PBLT activity before the main PBLT tasks to build the environment where the participants sharing the same L1 (Japanese, in our case) maintain the predominant use of L2 (English). Before Japanese students work on a project in an EFL class at our university, they participated in four online intercultural communication sessions with Chinese and Vietnamese university students. The purpose of this intercultural communication is to develop the communicative confidence in English and prime the Japanese EFL learners to the "English mode" of communication for the subsequent tasks, in

* Corresponding author: youngheo@u-aizu.ac.jp 
which they work with other Japanese students. The communication during the PBLT tasks in this course including the four preparatory sessions before the main meetings was via Zoom (technology-mediated PBLT), which, we believe, also contributed to the continued use of L2 in the main PBLT session among Japanese learners.

\section{Challenges of PBLT in an EFL Context}

PBLT is rooted in 'learning by doing' [1] and known for its great potential to teach language learners a wide range of academic skills (e.g., problem-solving and critical thinking) as well as the communicative skills in the target language. PBLT focuses on 'the collaborative learning and learning through tasks' [2] as students work toward the goal of a project. A project, in many contexts of PBLT studies, can be defined a 'long-term activity that involves a variety of individual or cooperative tasks' [3]. Despite the great outcome we can expect from PBLT when it is properly implemented, some EFL-specific issues negatively affecting the implementation of PBLT make many EFL educators believe that PBLT is not well suited for EFL classes.

Grant [4] stated that the lack of access to authentic English resources as shown in cases of [5] can be one of the difficulties in implementing PBLT in an EFL context by pointing out 'the access to authentic language or language speakers is important for students without prior PBLT experience' [4, pp.134]. Particularly, limited (or no) access to target language speakers give them less chance to communicate in L2 for authentic meaningful use of it. Another challenge regarding the use of L2 is found in in-class communication with other EFL students. For EFL students sharing the same L1, one of the pitfalls of working toward the real-life goal is to focus more on the completion of the task rather than practicing L2 communication with other group members. Students naturally fall back to the use of L1, with which the communication is better and faster, for the better result in their project. Especially for EFL learners with low English proficiency, the chance is higher for them to communicate predominantly in $\mathrm{L} 1$ as the project proceeds.

The goal of this study is to implement a pre-PBLT activity of intercultural communication via Zoom to encourage the Japanese EFL learners to practice and maintain the use of L2 for their PBLT activities. To examine how much more confidently and comfortably they can speak English after the four preparatory intercultural communication sessions, participants were asked to self-evaluate their confidence in L2 speaking before and after the treatment. Even after the completion of the intercultural communication, their mode of communication for the main activities in the PBLT remained online (even though all the Japanese students were physically gathered in the same classroom) to maintain the "English mode" of communication, which they practiced to adapt themselves to during the preparatory session. Their L2 speaking confidence was reported again using the same self-evaluation questions used for pre- and post-intercultural communication to further examine whether they could successfully maintain the use of English with their Japanese classmates and gain more confidence in speaking English.

\section{Method}

\subsection{Participants}

The participants in this study were Japanese university students majoring in computer science and engineering. Twenty-seven junior and senior students participated, and their English proficiency ranged from novice to low-intermediate (their average TOEIC score was 380). These students were enrolled in an English presentation skills class which was designed to 
be a project-based class with a real-life goal. Twelve international students (six Chinese and six Vietnamese) studying at the same university joined the class on Zoom for one hour per session (four hours in total) for the pre-PBLT intercultural communication activity.

\subsection{Pre-PBLT Intercultural Communication}

In the total of 15 class meetings, the main activity of the project in this course started from Class 7. During the first six class meetings, Japanese students took some lectures about presentation techniques. Along with the lecture part, Japanese participants communicated with Chinese and Vietnamese international students (6 each, 12 in total) via Zoom during the second half of each class meeting between Class 3 and Class 6. On Zoom, participants were divided into 10 to 12 groups with at least one international student present in each group. Participants discussed the topics provided before the class, and Chinese and Vietnamese participants, who were hired as teaching assistants, were asked to take the role of moderator as well as the discussant to encourage Japanese participants to speak and be given a chance to talk as much as possible.

\subsection{Design of the Project}

In this course, the final project was to provide students' ideas and plans for the remodeling of the school coffee shop. The university actually had a plan to remodel the small on-campus coffee shop because there were less than 10 customers visiting the place a day. The school was inviting ideas from students about the direction of this remodeling process, and the ideas and plans proposed in the course could possibly be adopted by the university as an initial plan for the bigger project. Students visited the coffee shop to interview the owner for his opinions and concerns about the current situation and brainstormed how the place can attract more customers. They also surveyed other students outside the class to ask about their experience of this coffee shop and investigate their demands. After their research of the current situation, each group (mostly 3 members) brainstormed their direction to approach this problem and further developed their ideas about how to remodel the coffee shop with a specific theme (e.g., gaming cafe and English cafe). Although the students enrolled in this course were taking the class face-to-face in the same classroom, the main communication for the group discussion was kept predominantly online via Zoom. As a final goal of this project, each group presented their ideas and plans as well as the process of how they developed their plan.

\subsection{Pre-test and the Two Post-tests}

The Japanese EFL learners took the same survey measuring the L2 speaking confidence at three different points in the course: 1) Class 1,2) Class 6 with the completion of the four intercultural communication sessions (pre-PBLT activity), and 3) Class 15 with the completion of the project. Two post-tests were conducted to see the effect of intercultural communication on their L2 speaking confidence and the continued use of L2; to see whether this pre-PBLT activity boosts the L2 speaking confidence and set the mode of using L2 among Japanese participants during the main project session.

For the survey, 'Confidence in Speaking Questionnaire' designed by Griffee [6] was utilized. He defined the L2 speaking confidence with three aspects: Ability, Assurance, and Willing engagement. Ability indicates "a command of grammar, vocabulary, and pronunciation," Assurance "a feeling of security and comfort in speaking English," and Willing engagement a feeling of being "glad to speak English with native speakers of 
English" [6, pp.187]. The key terms in his questionnaire Ability, Assurance, and Willing engagement are associated with those factors which are important in describing confidence. Four questions of each type (12 questions in total) were provided, and participants answered each item on a scale of five (1 indicating "not confident at all" and 5 indicating "very confident"). The higher the value is, the more confident he/she feels.

\section{Results and Discussion}

\subsection{Overall Impression}

Twenty-five students out of 27 students enrolled completed the course and many students participated in the pre-PBLT and the main PBLT activities. In Figure 1, what is on the left is the picture of students participating in the intercultural communication on Zoom, and what is on the right shows Japanese students communicating with other Japanese group members via Zoom.
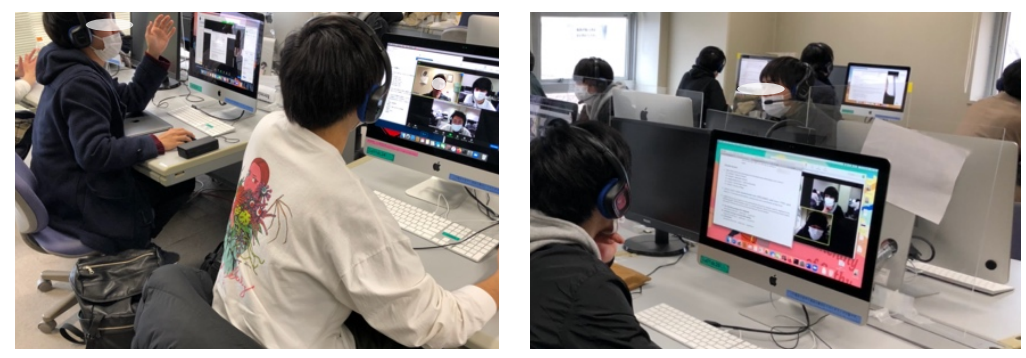

Fig. 1. Students communicating with international students (left) and Japanese group members (right)

In both types of sessions, students were very much engaged in the Zoom discussion in English. In their reflective writing after the four intercultural communication sessions, many Japanese EFL learners reported that they enjoyed their interaction with the international friends very much.

\subsection{Effectiveness of the Pre-PBLT Intercultural Communication}

\subsubsection{Overall Result}

Seventeen out of 27 Japanese students enrolled in the course participated in all three rounds of the L2 speaking confidence survey, so the result was analyzed for only those 17 students. The overall result of the change in the L2 speaking confidence level in the three stages of the course exhibits growing L2 confidence toward the completion of the course: pre-test (Average: 1.7), post-test 1 (Average: 2.3 ) and post-test 2 (Average: 2.54 ). The result suggests that the preparatory intercultural communication session could positively influence the L2 speaking confidence of Japanese EFL learners' and help them set the L2 mode of communication for the following activities with other Japanese speakers. 


\subsubsection{Individual Result}

Out of 17 participants who submitted all three L2 speaking confidence surveys, 15 students reported higher confidence level in the post-test 1 conducted immediately after the completion of intercultural communication. Among these 15 participants, 10 students could either achieve higher confidence (8 participants) or keep the same level of L2 speaking confidence ( 2 participants) in the post-test 2 conducted after the completion of the project. So for these participants, we can conclude that the intercultural communication could successfully help them build the mode of L2 communication, and they could maintain L2 speaking mode in the subsequent tasks with other Japanese speakers. The remaining 5 students who exhibited slight fall in the last post-test after the initial rise in the first post-test could be the ones who failed to keep the L2 mode of communication with their Japanese partners.

\section{Conclusion}

In this study, we reported on the effect of pre-PBLT intercultural communication in facilitating the continued use of L2 during the project of PBLT in an EFL context. Online intercultural communication with Chinese and Vietnamese students led the Japanese EFL students in this study to build confidence in English speaking. Via this experience of communicating in L2 and also by keeping the online mode of communication, Japanese EFL learners could continue to communicate in English even with their Japanese partners in the course of their project.

\section{References}

[1] J. Dewey, E. Dewey, The Schools of Tomorrow, Dutton, New York (1915)

[2] T. Hedge, English Lang Teaching J, 47, 276-277 (1993)

[3] G. Beckett, TESL Canada J, 19, 2, 52-66 (2002)

[4] S. Grant, Asian-Pac J of Sec and Foreign Lang Edu, 2, 1 (2017)

[5] Y. Guo, Project-based English as a foreign language education in China: Perspectives and issues, in G. Beckett, P. Miller (eds.), Project-based second and foreign language education, Information Age Publishing, Greenwich, pp143-158 (2006)

[6] D. Griffee, JALT J, 19, 2, 177-197 (1997) 